\title{
STUDY OF THE EFFICIENCY OF THE INHIBITORY EFFECT OF ANTIMICROBIAL PREPARATIONS IN THE PRODUCTION OF SUGAR SUBSTANCES
}

\author{
Nataliia Husiatynska \\ Department of Sugar Technologies and Water Treatment ${ }^{l}$ \\ Svitlana Teterina \\ Department of Biotechnology and Microbiology ${ }^{l}$ \\ Nataliia Hryhorenko $\bowtie$ \\ Laboratory of Molecular Genetic Analysis and Technological Quality \\ Institute of Bioenergy Crops and Sugar Beet of the National Academy of Agrarian Sciences of Ukraine \\ 25 Klinichna str., Kyiv, Ukraine, 03141 \\ grygorenko.na@gmail.com
}

Olha Kalenik

Department of ecological safety and labor protection ${ }^{l}$

${ }^{1}$ National University of Food Technologies

68 Volodymyrska str., Kyiv, Ukraine, 01601

$\triangle$ Corresponding author

Abstract

This article presents the relevance of the issue of inhibition of microbiological processes at different stages of processing of sugar-containing raw materials, in particular ensuring the microbiological purity of juices and syrups in the production of sugar substances. Information on the composition of microbiota contaminating raw materials in the production of beet sugar, raw cane sugar, food syrups from sugar sorghum is analyzed.

Experimental data on the evaluation of the effectiveness of a number of antimicrobial preparations in terms of growth retardation of pure cultures of microorganisms and the effect of disinfection during the introduction of preparations are presented.

The greatest danger in production is caused by the development of spore-forming and mucus-forming bacteria, which led to the choice of research objects.

Thus, the effect of antimicrobial preparations on microorganisms: mesophilic bacteria Bacillus subtilis, B. megatherium, thermophilic bacteria B. stearothermophilus, mucus-forming bacteria of the genus Leuconostos, was investigated. In addition, the effect of antimicrobials on mycelial fungi of the genus Aspergillus was studied.

Based on the conducted experimental studies, the range of costs of the studied antimicrobial preparation for the suppression of contaminating microflora in the production of sugar and food syrups from vegetable raw materials was determined.

Keywords: sugar beets, sweet sorghum juice, microbiota, effectiveness antimicrobial preparations, microbiota composition.

DOI: $10.21303 / 2504-5695.2021 .001982$

\section{Introduction}

Sugar beets, sugar cane and sugar sorghum are mainly used as raw materials for the production of sugar substances. These plant raw materials are characterized by a certain microbiota, which in production conditions can cause loss of sugars and deterioration of product quality.

In the production of sugars, spoilage is an exceptional consequence that can occur over a number of undesirable factors. In this case, we are talking just about the deterioration of quality.

The main raw material for sugar production in Ukraine is sugar beet. At the same time, climatic conditions allow the cultivation of sugar sorghum, which can be used quite successfully as an alternative sugar-containing raw material for food syrups [1]. In addition, sugar beet plants 
process raw cane sugar, obtained from sugar cane, in the off-season. Compliance with sanitary and hygienic requirements is an important element in the food quality and safety management system. The production of sugar and food syrups requires the application of sanitary measures and good production practices in accordance with the HACCP system (Hazard Analysis and Critical Control Points).

The course of microbiological processes at different stages of processing of sugar-containing raw materials leads to the decomposition of sucrose and the accumulation of metabolic products in juices and dense products. Thus, in addition to the loss of raw materials and sucrose, the development of microorganisms negatively affects the quality of technological products and sugar yield in general. In case of violation of technological regimes and non-compliance with sanitary and hygienic conditions of production, the content of microorganisms in intermediates increases significantly, which can lead not only to loss of sucrose, but also negatively affects the safety of finished products [2].

It is known, that the native microbiota of raw sugar can cause loss of sucrose during its storage. Typical representatives of sugar beet microbiota are micromycetes of the genera Botrytis, Phoma, Fusarium, Penicillium, Mucor, Rhizopus, Aspergillus, Trichothecium, Verticillium, Gliocladium, Trichoderma, as well as bacteria Bacillus subtilis, Leuconostoc mesenteroides, L. dextranicum and so on. [2, 3]. According to [4], the average total content of microorganisms in raw cane sugar is $7.8-10 \cdot 10^{3} \mathrm{CFU}$ per $10 \mathrm{~g}$, including: mycelial fungi $-5.1-6.5 \cdot 10^{3}$; bacteria $-0.95-2.7 \cdot 10^{3}$, and yeast $-3-11 \cdot 10^{2} \mathrm{CFU}$ per $10 \mathrm{~g}$. Among the species composition of mycelial fungi of raw cane sugar, about 20 members of the genera Verticillium, Rhizopus, Botrytis, Alternaria, Penicillium, Aspergillus, Mucor were found.

Microbiological parameters of the juice, obtained from the processing of sugar sorghum, differ in the qualitative and quantitative composition of microbiota. Thus, in the samples of juice, obtained by pressing during the processing of sugar sorghum variety "Nectar" [5], mainly bacterial and yeast cultures were found. After the analysis of morphological-cultural and physiological-biochemical characteristics of the isolated cultures, it was found, that they are similar in most respects to yeasts of the genera Saccharomyces, Rhodotorula and bacteria of the genera Lactobacillus, Leuconostoc and Streptococcus.

Studies [6] showed that the average number of microorganisms in freshly squeezed sorghum juice was $2 \cdot 10^{11} \mathrm{CFU} / \mathrm{ml}$. The predominant populations were yeast, lactobacilli and non-fecal colipoid bacteria. The dominant bacteria were Leuconostoc mesenteroides, as well as bacteria of the genera Acinetobacter, Enterobacter, Erwinia, and Pseudomonas. The dominant yeast was Candida intermedia, and Candida krusei, Saccharomyces cerevisiae, Saccharomyces montanus, Cryptococus spp, Pichia membranaefaciens, Rhodotorula spp. were also contained [6].

Thus, on the basis of the given data it is possible to draw a conclusion concerning urgency of a question of reception of finished goods under condition of the minimum microbiological contamination of sugar juices and dense products. It should also be noted that, despite the different nature of sugar-containing raw materials, the microbiota is generally represented by similar genera of microorganisms.

The course of microbiological processes in the production of sugar and food syrups depends on the characteristics of the technological process. Thus, during the main stages of the technological process of sugar production from beets, representatives of the mycelial microbiota do not develop, because the optimal temperature of their development is below $50{ }^{\circ} \mathrm{C}$. However, micromycete spores are able to withstand high enough temperatures, which can cause microbiological contamination of sugar and molasses. Thus, according to DSTU 4623:2006, the content of molds in $1 \mathrm{~g}$ of sugar should not exceed 1.0 10 CFU. According to DSTU 3696-98, the content of molds in molasses should not exceed $1.5 \cdot 10^{4}$ CFU. Particularly relevant is the issue of disinfection of the mycelial microbiota in the processing of raw cane sugar, due to the significant content of micromycetes in raw sugar and the lack of long-term effect of high temperatures in the production process [4]. Under such conditions, there is a high probability of maintaining the viability of micromycete spores.

In sugar production, the bacterial microbiota poses a significant danger, in particular during the extraction of sucrose from beet chips [2,7], or the production of juice from sorghum stalks [5]. 
Thus, during the processing of sugar beets, affected by clamp rot, a significant part of the beet microbiota is introduced into the diffusion apparatus: spore-forming aerobes Bacillus subtilis, B. mesentericus, B. megatherium, B. stearothermophilus, lactic acid bacteria: Lactobacterium brevis, L. buchneris, L. plantarum, at the development of mucous bacteriosis - Pseudomonas fluorescenes, Erwinia betaticola, Leuconostoc mesenteroides, L. dextranicum, yeast of the genus Saccharomyces $[8,9]$. In the process of extraction of sucrose from beet chips, microorganisms to some extent adapt to existing conditions, which can lead to the emergence of new properties that make them more resistant to various factors, including temperature, $\mathrm{pH}$, chemical reagents [8].

As a result of metabolic processes of these representatives of the microbiota is the decomposition of sugars and proteins of plant tissues with the formation of ammonia, acetone, acetaldehyde, $\beta$-oxybutyric acid, organic acids, $\mathrm{CO}_{2}, \mathrm{H}_{2}$. In addition, due to the development of a number of bacterial representatives of the microbiota in sugar solutions, polysaccharides dextran and levan forms, which leads to the mucus formation in process juices $[10,11]$.

Thus, due to the activity of microorganisms, and especially mucus-forming bacteria in juices and intermediates of sugar production, there are significant changes in the chemical composition, accompanied by decomposition of sucrose, increased content of reducing substances and organic acids, formation of high molecular weight polymers of glucose and fructose. Thus, the negative impact of the products of life of microorganisms is manifested in:

- reducing the quality of intermediate products;

- increasing the loss of sucrose in production (by increasing the sucrose content in molasses);

- deterioration of the filtration properties of juices in the cleaning process;

- distortion of sucrose content indicators in beets in the polarimetric method of determination (due to the increase in the content of reducing substances) and, accordingly, the purity of cell and diffusion juices.

In this regard, it is necessary to constantly maintain the proper sanitary condition of production and to carry out antimicrobial treatment of certain parts of the technological process. Thus, in the production of sugar from beets, it is advisable to use antimicrobial preparations during laying sugar beets in clamps, rinsing beets after washing, treatment of water for various purposes, juice-chipping mixture, clearing etc. [2]. In the case of processing raw cane sugar, the stage of clearing raw sugar and filtering syrups is important $[4,12]$. When processing sugar sorghum, the control of microbiological parameters of press and diffusion juices and finished syrups is urgent.

According to modern requirements, the active substances of antimicrobial preparations must have a wide range of biocidal effect, be non-toxic and eco-friendly [13, 14]. An important condition for the use of antimicrobial preparations in production is the absence of negative impact on the product quality.

The aim of the research was to study the effectiveness of a number of antimicrobial preparations in inhibiting the activity of a number of representatives of the contaminating microbiota in the production of sugars. To achieve this goal, the following research objectives were selected:

- to determine the sensitivity of the most characteristic representatives of the microbiota in sugar substances production to a number of active substances of antimicrobial preparations, recommended for use in sugar substances production;

- to determine the rational concentrations of active substances and to compare the effectiveness of the preparations on the example of disinfection of diffusion juice in the production of sugar from beets.

\section{Materials and Methods}

1. To determine the sensitivity of microorganisms to antimicrobial drugs, the method of diffusion of holes in the agar layer was used [15].

Objects of research:

- antimicrobial preparations: "Javel-Clayd", "Sanitarin" (active substance - active chlorine: sodium salt of dichloroisocyanuric acid); "Biodes" (polyhexamethylene guanidine hydrochloride); "Nobak" (antibiotic: citroside), "Bensteril" (sodium dimethyldithiocarbamate), HSG des 6 (glutaraldehyde); 
- test cultures of microorganisms: pre-isolated from diffusion juice, pure cultures of bacteria (Bacillus subtilis, Leuconostoc mesenteroides) and fungi (Aspergillus niger).

The studies were performed using the following nutrient media: meat peptone agar - for incubation of bacteria, wort agar - for incubation of micromycetes.

The sequence of the experiment. Pre-melted and cooled to the optimum temperature for each group of microorganisms, the nutrient media were infected by adding a suspension of daily culture of bacteria, or spore suspension in the case of micromycetes. The infected media were poured into sterile Petri dishes. After solidification of the nutrient medium, holes were made at a distance of 1.5-2.0 cm from the edge of the cup by a sterile drill. Aqueous solutions of antimicrobial preparatons of various concentrations were added to the holes. The cultures were incubated in the case of studying bacterial cultures at a temperature of $(37 \pm 0.5)^{\circ} \mathrm{C}$ for 24 hours, and in the case of studying micromycetes at a temperature of $(27 \pm 0.5){ }^{\circ} \mathrm{C}$ for 72 hours.

Interpretation of the results. The absence of a zone of growth retardation indicates that the studied culture is not sensitive to the action of this antimicrobial preparation. When the diameter of the zone is up to $15 \mathrm{~mm}$, it is considered that the microorganisms have a low degree of sensitivity to the test preparation, the diameter of the zone from 15 to $25 \mathrm{~mm}$ indicates a medium degree of sensitivity. The presence of a zone with a diameter of more than $25 \mathrm{~mm}$ indicates a high degree of sensitivity of microorganisms to this antimicrobial preparation.

2. To confirm the effectiveness of the antimicrobial action of the studied preparations in production conditions, the modeling of the extraction process (obtaining diffusion juice) under laboratory conditions was performed. The total content of microorganisms in the samples of diffusion juice was determined by the method of Koch [15] by successive ten-fold dilutions and inoculation on a dense nutrient medium. Incubation of cultures was performed at a temperature of $(37 \pm 0.5){ }^{\circ} \mathrm{C}$ for 48 hours on meat peptone agar.

The effectiveness of disinfection was determined by the difference in the content of microorganisms in the diffusion juice before $\left(X_{1}\right)$ and after $\left(X_{2}\right)$ administration of antimicrobial preparations and was expressed in \%: Ef.v $=100 \cdot\left(X_{1}-X_{2}\right) / X_{1}$.

\section{Results and Discussion}

Since the species microflora in the production of sugar substances has a similar character, the selected microorganisms can be markers of the effectiveness of disinfectant action at different stages of production of sugar and food syrups from different sugar raw materials. In particular, we considered sugar beets, cane raw sugar, sugar sorghum as raw materials [2, 4, 5].

The research results of the effectiveness of the above antimicrobial preparations on certain types of microorganisms of the contaminating microbiota are given in Tables 1-3. Conclusions about the effectiveness of antimicrobials were made in the presence of a zone of growth retardation of microorganisms.

Table 1

The sensitivity degree of spore-forming bacteria (Bacillus subtilis)

\begin{tabular}{ccccc}
\hline & \multicolumn{4}{c}{ Action zone diameter of the antimicrobial preparation, $\mathbf{m m}$} \\
\cline { 2 - 5 } Preparation & \multicolumn{4}{c}{ Active substance consumption, $\mathbf{~}$} \\
\cline { 2 - 5 } & 32 & $\mathbf{0 . 0 0 2}$ & $\mathbf{0 . 0 0 4}$ & $\mathbf{0 . 0 0 6}$ \\
\hline Javel-Clayd & 33 & & Absent growth & Absent growth \\
Sanitarin & 20 & 28 & 34 & Absent growth \\
Nobak & 28 & 32 & 33 & 34 \\
Bensteril & 22 & 33 & 39 &
\end{tabular}


Table 2

The sensitivity degree of mucus-forming of the genus Leuconostoc

\begin{tabular}{ccccc}
\hline \multirow{2}{*}{ Preparation } & \multicolumn{4}{c}{ Action zone diameter of the antimicrobial preparation, $\mathbf{m m}$} \\
\cline { 2 - 5 } & $\mathbf{0 . 0 0 1}$ & $\mathbf{0 . 0 0 2}$ Active substance consumption, $\mathbf{g}$ \\
\cline { 2 - 5 } & 29 & 34 & $\mathbf{0 . 0 0 4}$ & $\mathbf{0 . 0 0 6}$ \\
\hline Javel-Clayd & 30 & 36 & & Absent growth \\
Sanitarin & 16 & 25 & 29 & 32 \\
Nobak & 23 & 28 & 36 & 40 \\
Bensteril & 15 & 31 & 38 & 31 \\
HGS des 6 & 16 & 24 & 28 &
\end{tabular}

Table 3

The sensitivity degree of mycromycetes Aspergillus niger

\begin{tabular}{|c|c|c|c|c|c|}
\hline \multirow{3}{*}{ Preparation } & \multicolumn{5}{|c|}{ Active substance consumption, $g$} \\
\hline & 0.0002 & 0.0005 & 0.001 & 0.002 & 0.003 \\
\hline & \multicolumn{5}{|c|}{ Action zone diameter of the antimicrobial preparation, $\mathbf{m m}$ at $t=25^{\circ} \mathrm{C}$} \\
\hline Javel-Clayd & Total growth & 5 & 12 & 16 & 20 \\
\hline Sanitarin & 4 & 13 & 20 & 38 & Absent growth \\
\hline Biodes & \multicolumn{2}{|c|}{ Total growth } & 5 & 10 & 18 \\
\hline Bensteril & 12 & 18 & 26 & 38 & 44 \\
\hline HGS des 6 & \multicolumn{2}{|c|}{ Total growth } & 7 & 14 & 17 \\
\hline
\end{tabular}

Note: The preparation "Nobak" did not show an inhibitory effect on the fungal microbiota, even in the case of a significant concentration increase

The presented results (Tables 1-3) are evidence that antimicrobial preparations based on dichloroisocyanuric acid (Javel-Clayd, Sanitarin) have the high antimicrobial effect against bacteria and micromycetes. There should be noted their high efficiency against bacteria Bacillus subtilis and mucus-forming bacteria of the genus Leuconostos. However, it should be noted, that the fungicidal effect of these preparations on fungi of the genus Aspergillus is much less. The sterility of the medium in the Petri dish is achieved by using the preparation "Sanitarin" in the amount of $0,003 \mathrm{~g}$, which is 5-10 times higher than the average consumption of the preparation in the case of affecting bacteria.

It is also possible to note the high efficiency of "Bensteril" and "HSG des 6", which at increase of their dosage also show the high efficiency, as in the case of application of preparations on the basis of active chlorine. When Nobak is used to inhibit the bacterial microbiota, the results confirm its effectiveness, but it is ineffective in inhibiting fungi, even in the case of a significant increase in concentration.

Therefore, the optimal range of consumption for destructing the contaminating microbiota is in \% of the product weight: "Javel-Clayd" and "Sanitarin" - 0.001-0.002, "Biodes" - 0.002-0.004, "Bensteril" and "HSG des 6" - 0.0015-0.0025, Nobak - 0.003-0.005.

Comparative studies of the effectiveness of the disinfectant action of the studied preparations during the extraction of sucrose from beet chips were also carried out (Fig. 1). The consumption of each of the antimicrobial preparations corresponded to the range, determined on the basis of previous studies (Tables 1-3), recommended for use in the technological process. The total content of microorganisms in the diffusion juice before the introduction of antimicrobials was $4.2 \mathrm{CFU}$ (colony-forming microorganisms) million $/ \mathrm{cm}^{3}$.This indicator corresponds to the range of the total number of microorganisms in factory diffusion juice, namely: about 100 thousand-10 million $\mathrm{CFU} / \mathrm{cm}^{3}$. After the introduction of antimicrobials, the total content of microorganisms ranged from 0.17 to $0.42 \mathrm{CFU}$ million $/ \mathrm{cm}^{3}$. Fig. 1 shows the effects of disinfection of diffusion juice by antimicrobial preparations at certain values of consumption of the active substance to the juice weight. 
According to the obtained data, the studied antimicrobial preparations have the high disinfection effect on the microflora of diffusion juice. Thus, the effect of disinfection of microorganisms present in the diffusion juice as $90-95 \%$ is achieved with the use of the preparations: based on active chlorine in the amount of $0.0008 \%$; Bensteril and HSG des $6-0.002 \%$; "Biodes" $0.003 \%$; Nobak - $0.006 \%$.

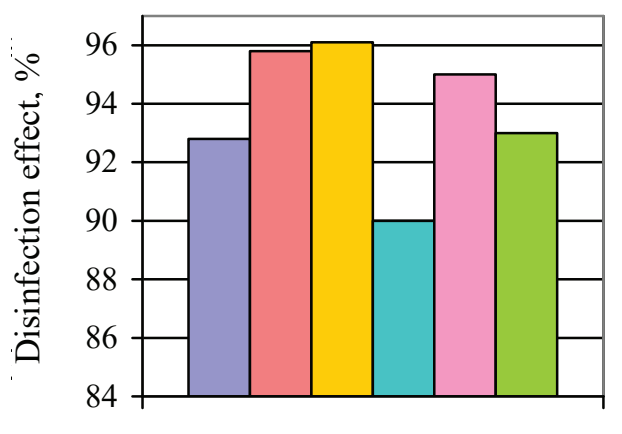

$\square$ Biodes, 0.003

$\square$ Javel-Clayd, 0.0008

$\square$ Sanitarin, 0.0008

$\square$ морак, 0.006

$\square$ Bensteril, 0.002

$\square$ HGS6 des, 0.002

Fig. 1. Effect of diffusion juice disinfection at using antimicrobials, in $\%$ of the juice weight

\section{Conclusions}

The analysis of the results of the conducted researches testifies to the high efficiency of the preparations on the basis of sodium salt of dichloroisocyanuric acid. The nature of the toxic action of chemical compounds based on active chlorine is associated with oxidative processes in the protoplasm of a microbial cell, leading to its death. There should also be noted the high efficiency of "Bensteril" and "HSG des 6", but their consumption to achieve a similar effect is much higher compared to the preparations based on active chlorine. In the case of using the preparation "Nobak", due to its narrower spectrum of action (mainly bacterial microbiota), it is possible to recommend additional administration of fungicides.

Based on the conducted experimental studies, it is possible to recommend the use of antimicrobial preparations based on the sodium salt of dichloroisocyanuric acid in the amount of $0.001-0.002 \%$ of the product weight, citroside -0.004 , sodium dimethyldithiocarbamate $-0.0015-$ 0.0025 and glutaraldehyde $-0.0015-0.0025$ to destroy the contaminating microflora in the production of sugar and food syrups from vegetable raw materials.

\section{References}

[1] Skoryi, V. M. (2009). Enerhetychni roslyny v Ukraini. Kyiv: Feniks, 224.

[2] Husyatynska, N., Nechypor, T. (2017). The Efficiency of Modern Dezinfectants in the Sugar Beet Processing Affected by Bacteria of Leuconostoc. Scientific Works of National University of Food Technologies, 23 (6), 199-206. doi: https://doi.org/ 10.24263/2225-2924-2017-23-6-25

[3] Dvorak, E. P., Kots, S. Ya. (2017). Sugar Beet Diseases of Bacterial Etiology. Fiziologia rastenij i genetika, 49 (5), $398-404$. doi: https://doi.org/10.15407/frg2017.05.398

[4] Husiatynska, N. A., Teterina, S. M., Romanchenko, N. M. (2011). Analiz mikrobiolohichnykh protsesiv pid chas pereroblennia trostynnoho tsukru-syrtsiu. Kharchova promyslovist, 10, 8-12. Available at: http://dspace.nuft.edu.ua/jspui/handle/ $123456789 / 693$

[5] Korolenko, A., Karputina, D., Teterina, S., Karputina, M. (2014). Determination of microbiological and physicochemical characteristics of sweet sorghum and wort on its base in the non-alcoholic drinks technology. Scientific horizons. Medicine. Biological sciences. Science and and education LTD, 8, 73-78. Available at: http://dspace.nuft.edu.ua/jspui/handle/ 123456789/20769? mode=full

[6] Daeschel, M. A., Mundt, J. O., McCarty, I. E. (1981). Microbial Changes in Sweet Sorghum ( Sorghum bicolor ) Juices. Applied and Environmental Microbiology, 42 (2), 381-382. doi: https://doi.org/10.1128/aem.42.2.381-382.1981

[7] Hein, W., Roesner, G., Emerstorfer, F. (2008). Measures to prevent operational disturbances caused by dextran. Sugar Industry, 133 (3), 135-143. 
[8] Kulneva, N. G., Shmatova, A. I., Man'ko, I. I. (2014). Microflora of beet sugar production: problems and solutions. Proceedings of the Voronezh State University of Engineering Technologies, 1, 193-196. Available at: https://www.vestnik-vsuet.ru/vguit/ article/view/736/703

[9] Noori, S., Naghavi, N. S., Mohammadi Sichani, M., Gol Gol Jam, M., Zia, M. A. (2014). Identification and biological control of microbial agents causing corruption of stored sugar beets in sugar production industry. Journal of Sugar Beet, 29 (2), 79-85.

[10] Helemskiy, M. Z., Pel'ts, M. L., Sapozhnikova, I. R. (1977). Biohimiya v sveklosaharnom proizvodstve. Moscow: Pischevaya promyshlennost', 224.

[11] Iciek, J., Ludwicki, M., Chmal-Fudali, E. (2015). Control of microbial contamination of juice in a tower extractor by measuring redox potential. Sugar Industry, 140 (3), 149-155. doi: https://doi.org/10.36961/si16359

[12] Golybin, V. A., Chernyaeva, V. A., Isaevskaya, A. K. (2001). Mikrobiologicheskaya zagryaznennost' sahara-syrtsa. Sahar, 3, $18-20$.

[13] BS EN 12353:2006. Chemical disinfectants and antiseptics. Preservation of test organisms used for the determination of bactericidal, sporicidal and fungicidal activity. doi: https://doi.org/10.3403/30143742

[14] BS EN 14885:2006. Chemical disinfectants and antiseptics. Application of European Standards for chemical disinfectants and antiseptics. doi: https://doi.org/10.3403/30110413

[15] Hrehirchak, N. M. (2009). Mikrobiolohiya kharchovykh vyrobnytstv. Kyiv: NUKhT, 302.

How to cite: Husiatynska, N., Teterina, S., Hryhorenko, N., Kalenik, O. (2021). Study of the efficiency of the inhibitory effect of antimicrobial preparations in the production of sugar substances. EUREKA: Life Sciences, 4, 43-49. doi: https://doi.org/10.21303/25045695.2021 .001982 